\title{
EDUCAÇÃO AMBIENTAL: TRABALHANDO O USO RACIONAL DA ÁGUA NAS SÉRIES INICIAIS
}

\author{
Maria Eunice Garcia Rodrigues', Toshio Nishijima² \\ ${ }^{1}$ Acadêmica da Especialização em Educação Ambiental da UFSM \\ ${ }^{2}$ Professor orientador da UFSM
}

\section{RESUMO}

O objetivo geral deste estudo foi propiciar aos alunos conhecimento sobre a importância dos cuidados que devemos ter com a água, e que é através da mudança de valores e atitudes que poderemos contribuir para uma melhor qualidade de vida e ajudar na preservação desse importante recurso natural. As atividades foram desenvolvidas com os alunos do 10 e 20 ano e da 3a e 4a serie, da Escola Municipal de Ensino Fundamental, São João Batista, no Município de Formigueiro-RS. Através deste objetivo geral buscou-se alcançar os seguintes objetivos específicos: proporcionar aos alunos o entendimento da importância da água para a vida do ser humano, despertar o interesse dos alunos sobre o tema, criar jogos e textos para avaliar o trabalho desenvolvido. Promover a educação ambiental através de temas sobre recursos hídricos. Foram usadas técnicas como: questionário, observações, produção de texto, jogos e passeio. Foi possível observar, com a aplicação destas técnicas, que o tema Educação Ambiental é relevante no sentido de sensibilizar os pais e alunos sobre o uso racional da água, bem como os cuidados com a sua preservação.

Palavras-chave: água, preservação, qualidade, educação ambiental

\section{INTRODUÇÃO}

Toda a atividade humana gera impacto no meio ambiente, que pode ser positivo ou negativo. Pela pouca compreensão que tem-se das relações e interdependências entre os seres vivos e as demais formas naturais existentes no planeta, acabamos degradando mais do que melhorando as condições ambientais.

A educação ambiental possibilita conhecimentos para que se estabeleça com a natureza uma relação harmoniosa. Afinal, é da natureza que fazemos parte e retiramos o que é necessário para a nossa sobrevivência, até o fim das nossas vidas.

Entender e respeitar os ciclos da natureza é condição indispensável para o melhor desenvolvimento das atividades culturais, sociais e econômicas das comunidades. Diminuir os conflitos entre as necessidades humanas e as condições de sustentação da natureza, são os objetivos a serem alcançados pela educação ambiental.

Mas a natureza tem recebido uma carga de dejetos e muitas outras ações predatórias produzidas pelas atividades humanas e sociais.

Com isso as exigências sociais têm buscado um mundo melhor que permita ao ser humano agir em sociedade minimizando os efeitos danosos ao nosso ambiente natural.

Esta visão de mundo precisa ser construída a partir de uma nova concepção de educação 


\section{RODRIGUES \& NISHIJIMA, vol.(4), n4, p. 696-706, 2011. Monografias Ambientais (e-ISSN: 2236-1308)}

REMOA

ambiental que seja capaz de promover a formação de personalidades ambientais, aproximando a prática pedagógica ao processo de construção de conhecimento.

A educação ambiental é uma possibilidade de se provocar mudanças e alterar o atual quadro de degradação do ambiente e tornar as pessoas como agentes de transformação. Pois segundo Tozoni-Reis (2007):

A Educação Ambiental como promotora de mudanças de comportamentos ambientalmente inadequados - de fundo disciplinatório e moralista -; a educação ambiental para a sensibilização ambiental - de fundo ingênuo e imobilista a educação ambiental centrada na ação para diminuição dos efeitos predatórios das relações dos sujeitos com a natureza - de caráter ativista e imediatista; a educação ambiental centrada na transmissão de conhecimentos técnico-científicos sobre os processos ambientais que teriam como conseqüência uma relação mais adequada com o ambiente - de caráter racionalista e instrumental; e a educação ambienta como um processo político de apropriação crítica e reflexiva de conhecimentos, atitudes, valores e comportamentos que tem como objetivo a construção de uma sociedade sustentável do ponto de vista ambiental e social - a educação ambiental transformadora e emancipatória (TOZONI-REIS, 2007, p. 9).

Uma das questões ambientais que vem nos chamando muito a atenção nos últimos tempos é a questão da água. A água cobre quase três quartos da superfície terrestre e é um bem indispensável à atividade do homem. Sabe-se que a água é um recurso natural que desempenha papel fundamental para o equilíbrio ambiental e preservação de toda a vida no planeta.

E cada vez mais se torna difícil ter acesso à água devido a sua falta, seja pelo crescimento populacional, ou aumento da demanda, seja pela redução da oferta ou especialmente pela poluição dos rios. Principalmente a água potável que está se tornando cada vez mais escassa, o que torna sua preservação necessária e busca na defesa de sua qualidade.

É importante propiciar aos alunos os conhecimentos sobre meio ambiente a fim de que eles possam vivenciar o que esse tem a nos oferecer e lutar pela sua preservação.

O objetivo geral deste estudo foi propiciar aos alunos conhecimento sobre a importância dos cuidados que devemos ter com a água, e que é através da mudança de valores e atitudes que poderemos contribuir para uma melhor qualidade de vida e ajudar na preservação desse importante recurso natural.

Os objetivos específicos são:

a) proporcionar aos alunos o entendimento sobre a importância da água para a vida do ser humano;

b) despertar o interesse dos alunos sobre o tema;

c) criar jogos e textos para avaliar o trabalho desenvolvido;

d) promover a educação ambiental através de temas sobre recursos hídricos.

\section{REVISÃO DE LITERATURA \\ Meio Ambiente uma Questão de Educação}

Nos dias de hoje, em face de toda problemática ambiental que está atingindo a população do mundo inteiro, tornou-se premente a necessidade de serem observadas pequenas ações diárias 
que nos apontem responsabilidades em relação à gravidade da situação existente. Estas pequenas, mas muito importantes ações - tomadas de decisões - como o uso racional da água potável, reaproveitamento dos alimentos, reciclagem de resíduos sólidos tem sido fatores determinantes no combate ao processo degenerativo pelo qual passa o planeta terra.

A educação está presente na história da humanidade. Através dela o homem vem encontrando formas de relacionar-se com o meio que o cerca e vem transformando-o segundo suas necessidades e interesses.

A Educação Ambiental deve fazer parte da formação de todo o ser humano que pensa o futuro. A base para o indivíduo do século 21 compreender a natureza se faz necessária para estabelecer uma sintonia e entender as relações entre o homem e a natureza

\section{Recursos Hídricos}

A água é um dos recursos naturais que pode ser considerado como denominador comum de toda a humanidade. Afinal, todos os povos e culturas utilizam e precisam deste recurso para sobreviver. Por isso, afirma Selborne (2002), “a água (...) tornou-se também um símbolo de equidade social, pois a crise da água é sobre tudo, de distribuição, conhecimentos e recursos, e não de escassez absoluta." Por isso, devem-se levar em conta os princípios éticos na tomada de decisões relativas aos recursos hídricos, já que as estratégias a serem tomadas envolvem o problema de acesso e privação.

A vida gerou-se na água e existe na dependência desta, de tal forma que toda a estrutura viva é um depósito de água no qual se diluem substancias minerais e orgânicas em graus diversos de concentração. Tanto é assim que a natureza desenvolveu nos organismos vivos métodos por vezes bastante complexos de adaptação aos ambientes. E à medida que a escassez de água aumenta nesses ambientes, a capacidade de adaptação diminui, e o numero de espécies que neles são capazes de sobreviver decresce gradativamente ate a vida tornar-se todo impossível. (VASCONCELOS SOBRINHO, 1980)

\section{Água no Mundo}

Hidrologia é a ciência que estuda a água na terra sob os mais variados aspectos, quais sejam: sua ocorrência, sua circulação, distribuição, suas propriedades físico químicas e suas relações e sua relação como meio ambiente, incluindo sua relação com os seres vivos relacionada com toda a água da Terra. (CHOW, 1959).

A água doce utilizada pelo homem vem de represas, rios, lagos, açudes, reservas subterrâneas e em certos casos do mar (após um processo chamado dessanalização). A água para o consumo é armazenada em reservatórios de distribuição e depois enviada para grandes tanques e caixas d água de casas e edifícios. Após o uso, a água segue pela rede de captação de esgotos. Antes de voltar a natureza, ele deve ser novamente tratada, para evitar a contaminação de rios e reservatórios. 


\title{
RODRIGUES \& NISHIJIMA, vol.(4), n4, p. 696-706, 2011. Monografias Ambientais (e-ISSN: 2236-1308)
}

REMOA

\begin{abstract}
Existe no planeta cerca de 1,38 bilhão de quilômetros cúbicos $\left(\mathrm{Km}^{3}\right)$ de água. Destes, $97,3 \%$ são de água salgada e apenas

2,7\% o que equivale a 38 milhões de quilômetros cúbicos, de água doce. Em apenas 25 anos entre 1970 e 1995, houve queda de $37 \%$ no volume de água disponível no planeta. Cerca de $30 \%$ da população mundial já vive em regiões com falta ou escassez de água, e esse total pode chegar até $70 \%$ nos próximos 30 anos, se não forem tomadas sérias medidas de

conservação. Embora possua entre 13 e $20 \%$ das reservas de

água doce no planeta, de acordo com estimativas de diversas entidades internacionais, o Brasil também tem enfrentado graves problemas em relação a escassez do recurso, que é progressiva nos grandes centros urbanos do país. (SANTOS;IGLESIAS ,2001, p. 7)
\end{abstract}

Porém, a maior parte dessa água ou se encontra congelada nas calotas polares e nas geleiras ou se situa no subsolo.

A água está presente em múltiplas atividades do homem e, como tal, é utilizada para finalidades muito diversificadas, em que assumem maior importância o abastecimento doméstico e público, os usos agrícolas e industriais e a produção de energia elétrica.

\section{A Água no Brasil}

Segundo o Ministério do Meio Ambiente (1997), o Brasil detém 8\% de toda a água doce superficial do planeta. A maior parte da água disponível para o uso no Brasil, cerca de $80 \%$ está localizada na Região Amazônica e os $20 / \%$ restantes se distribuem, desigualmente, pelo resto do país para atender $95 \%$ da população Brasileira.

A maior parte da população - e da atividade econômica - do país está em grandes centros urbanos na região sudeste, mais próximos da Bacia do Prata, onde a oferta de líquido potável é cada vez mais escassa.

Apesar de deter grande parte do volume de água doce - sabe - se que a Amazônia contribui com $15 \%$ do volume de água disponível no mundo ( $\mathrm{TUCCl}$, et al.,2001) , o Brasil ainda não o gerencia de maneira correta, seja do ponto de vista do aproveitamento e das formas de exploração sustentáveis, seja em relação ao fornecimento de sistema de água e esgoto.

A água é um precioso recurso não renovável. Todos devem ter um grande respeito por esse bem, procurando manter seus reservatórios naturais e salvaguardar sua pureza, usando-a com sabedoria para reaproveitá-la ao máximo (reciclagem) e, neste caso, menos poluí-la, mais fácil será purificá-la para sucessivas utilizações.

\section{Qualidade da Água}

A água é fundamental para a sobrevivência do homem e para o equilíbrio de toda a natureza do planeta. Sua importância faz com hoje ela seja uma preocupação mundial diante das ameaças da poluição, do uso insustentável, das mudanças climáticas, das mudanças no uso do 


\section{RODRIGUES \& NISHIJIMA, vol.(4), n4, p. 696-706, 2011. Monografias Ambientais (e-ISSN: 2236-1308)}

REMOA

solo e risco de escassez. É preciso garantir a qualidade desse recurso vital, para que todos tenham acesso à água adequada para suas necessidades básicas.

O acesso a água potável torna-se cada vez mais difícil, especialmente pelo fato do homem contaminar em suas diversas formas, essa pequena quantidade que se tem disponível ainda em nosso planeta. A água mal tratada ou desprotegida pode estar contaminada. A contaminação da água é constada pela presença de microorganismos patogênicos capazes de causar doenças e até mesmo epidemias ou substancias químicas que fazem mal a saúde dos seres humanos. (BATALHA, 1985).

A participação da sociedade no progresso da defesa ambiental, da preservação e conservação dos recursos hídricos deve ser a meta de todos. A água faz parte do patrimônio do nosso planeta.

O direito à água é um dos direitos fundamentais do ser humano: o direito à vida, tal qual é estipulado no Art. 30 da Declaração Universal, dos Direitos Humanos (DDH, 2005).

\section{Poluição das Águas}

Um dos bens mais preciosos à disposição da humanidade é água, qual requer racionalidade e parcimônia em sua utilização. Como resultado de sua importância, a poluição das águas é uma das maiores preocupações dos ecologistas e de todos aqueles que necessitam utilizar a água com insumo em atividades econômicas.

Conforme apresentado por Valle (1995), em Qualidade Ambiental, racionalização do uso da água nas atividades promovidas pelo homem é o primeiro passo para reduzir os riscos da contaminação hídrica. Se forem menores os volumes de água utilizados e descartados pelas atividades de mineração, agricultura, indústria e serviços, menores serão naturalmente as necessidades tratamento e de seu recondicionamento às condições originais de pureza.

Desse modo, entende-se que esses espaços são ou podem vir a ser um local de desenvolvimento da EA, conforme a Lei 9.795/99, no seu Art.13으, que se refere "ações e práticas educativas voltadas à sensibilização da coletividade sobre as questões ambientais e a sua organização e participação na defesa da qualidade do meio ambiente", que para tanto devem ser planejadas de acordo com o perfil ambiental apresentado por uma determinada comunidade (DIAS, 2001).

\section{A Importância da Água para a Vida}

A importância da água para a vida provém das suas características físicas e químicas que por sua vez resultam da sua estrutura molecular (KRAMER; BOYER, 1995).

Na sua relação histórica com a água, o homem vivenciou momentos de extrema importância, em que a própria sobrevivência e a viabilização da vida em sociedade estiveram em jogo ou foram aprimoradas. KAISER (1952)

Recurso natural de valor econômico, estratégico e social, essencial à existência e ao bem estar do homem e à manutenção dos ecossistemas do planeta, a água é um bem comum a toda a humanidade.

Água é fonte de vida. Não importa quem somos, o que fazemos, onde vivemos, nós dependemos dela para viver. No entanto, por maior que seja a importância da água, as pessoas 


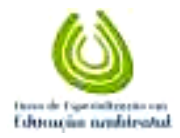

RODRIGUES \& NISHIJIMA, vol.(4), n4, p. 696-706, 2011.

Monografias Ambientais ～(e-ISSN: 2236-1308)

REMOA

continuam poluindo os rios e suas nascentes, esquecendo o quanto ela é essencial para nossas vidas.

\section{MATERIAIS E METODOS}

A coleta de dados foi realizada na escola municipal São João Batista, localizada no município de Formigueiro, situada na zona Rural. A população envolvida nesta pesquisa foram os alunos do Ensino Fundamental e os pais da comunidade onde vivem.

Depois de debatidos os assuntos sobre água, da importância de realizar sua economia, de onde vem a água que chega até as residências, os alunos responderam a um questionário o qual está inserido nos anexos do trabalho, onde consta perguntas referente ao que havia sido visto em aula.

Também foi realizada uma produção textual sobre o tema "Gotinha de Cristal", onde começava falando de uma gotinha que saiu em busca de uma aventura e os alunos deram continuidade a historinha.

A partir dos textos e trabalhos dados em aula foram confeccionados jogos como de quebra cabeça pelos alunos e dos lugares onde a água é encontrada na terra como o rio, mar, chuva, etc.

Os alunos pintaram os desenhos colaram em cartolina e depois recortaram os jogos, cada um fez o seu quebra-cabeça, depois fizeram um grande grupo e trocaram os jogos com os colegas para montarem.

Foi feito na sala de aula uma trilha no chão da sala onde os alunos jogavam um dado e conforme o numero que tiravam avançavam na trilha e tinham que responder perguntas relacionadas a água, na medida que avançavam no jogo seguiam a diante onde o ponto de chegada era um poço desenhado e colado na classe o qual era um dos lugares onde se encontra água.

A professora estimulava os alunos à curiosidade, à medida que iam jogando e respondendo, pois nem todas as perguntas eram sobre água, algumas tinham que voltar uma ou duas casas, ou então começar o jogo novamente como qualquer uma trilha sempre existem os obstáculos, mas o importante era não desistir e muitos contavam com a ajuda dos colegas para responder o que tornou o jogo mais interessante, pois todos participaram.

Foi realizado um passeio a casa de dois alunos para visitação aos poços, onde os alunos juntamente com as professoras realizaram uma exploração dos recursos locais (no caso os poços), próximos da escola o que permitiu observar como a água chegava até as residências e de como era utilizada, através deste passeio os alunos puderam vivenciar situações concretas.

Foi escolhido as casas de dois alunos que moram próximos da escola devido a muitos morarem longe, um dos poços era bem próximo à residência e a água tinha que ser retirada com balde o outro era longe e a água chegava até a residência através de uma moto-bomba.

$O$ instrumento para coletar os dados foi um questionário o qual consta nos anexos do trabalho; e este se constitui de uma série de perguntas respondidas por escrito pelos pais onde colocaram informações e opiniões sobre o assunto e outro questionário respondido pelos alunos. Junto com o questionário foi remetida uma nota explicando a natureza da pesquisa e sua importância, despertando assim o interesse no preenchimento do mesmo. 
Foram distribuídos 15 questionários (Anexo 3), um para cada família dos alunos, porém retornaram apenas 12 , o que não impediu a tabulação e análise dos mesmos. A grande parte da comunidade ainda não dispõe de água potável, ou seja, água tratada, a água utilizada por eles incluindo a da escola vem de poços artesianos, fontes e açudes.

O estudo foi realizado na comunidade da Para Luz no município de Formigueiro onde participaram os professores alunos e pais da escola São João Batista.

Também consta neste trabalho a análise da água do poço da escola o qual mostram duas análises e que a última análise feita no dia nove de março de dois mil e nove ficou constatada a contaminação da água do poço, sendo que este foi contaminado pelo poço negro o qual fica próximo.

A escola constava com apenas uma caixa d'água, mas a partir desta analise houve a necessidade de colocar-se outra, as duas são abastecidas uma vez por semana.

Após a coleta de dados os mesmos foram tabulados, analisados, interpretados por meio de tabelas.

\section{RESULTADOS E DISCUSSÃO}

O resultado das respostas obtidas na pesquisa referente a qualidade da água e de sua preservação para o meio ambiente no olhar dos pais da comunidade escolar estão apresentadas na Tabela 1. 
REMOA

Tabela 1. Respostas obtidas na pesquisa referente a qualidade da água e de sua preservação para o meio ambiente no olhar dos pais da comunidade escolar.

\begin{tabular}{|l|c|c|}
\multicolumn{1}{|c|}{$\begin{array}{c}\text { QUESTÕES } \\
\text { RESPOSTAS }\end{array}$} & SIM & NÃO \\
\hline 1. A água que você usa em sua casa vem de poço? & 9 & 3 \\
\hline 2. Você acha importante a preservação da água? & 12 & 0 \\
\hline 3. A água que você utiliza é de boa qualidade (tratada)? & 7 & 5 \\
\hline 4. Você acha que a água de boa qualidade faz bem a saúde? & 12 & 0 \\
\hline $\begin{array}{l}\text { 5. Você tem orientação de como se ter uma água de } \\
\text { qualidade? }\end{array}$ & 7 & 5 \\
\hline 6. Em sua residência existe algum tipo de poluição da água? & 4 & 8 \\
\hline $\begin{array}{l}\text { 7. Você acha que com o passar dos anos o uso deste recurso } \\
\text { mudou? Por quê? }\end{array}$ & 11 & 1 \\
\hline 8. Em sua casa você faz economia de água? & 10 & 2 \\
\hline $\begin{array}{l}\text { 9. Em sua opinião o que deveria ser feito para a preservação } \\
\text { da água? }\end{array}$ & 12 & 0 \\
\hline $\begin{array}{l}\text { 10. Você acredita que a Educação Ambiental está } \\
\text { contribuindo para a preservação da água? }\end{array}$ & 10 & 2 \\
\hline Total: & 12 & 0 \\
\hline
\end{tabular}

Fonte: Escola Municipal de Ensino Fundamental São João Batista 
Tabela 2: Respostas obtidas na pesquisa referente a qualidade da água e de sua preservação para o meio ambiente no olhar dos alunos da escola.

\begin{tabular}{|l|c|c|}
\hline \multicolumn{1}{|c|}{ QUESTÕES } & \multicolumn{2}{c|}{ RESPOSTAS } \\
\cline { 2 - 3 } & SIM & NÃO \\
\hline 1. Você conhece a utilidade da água? & 10 & 0 \\
\hline 2. Como e onde se encontra água na natureza? & 10 & 0 \\
\hline 3. O que você pode fazer para preservar a água? & 10 & 0 \\
\hline 4. Em sua casa o que você faz para economizar água? & 9 & 1 \\
\hline
\end{tabular}

\begin{tabular}{|l|c|c|}
\hline 5. Quais as formas de economizar água que você conhece? & 9 & 1 \\
\hline 6. Você acha importante estudar sobre a água e sua & 10 & - \\
preservação? Por quê? & 10 & - \\
\hline Total:
\end{tabular}

Fonte: Escola Municipal de Ensino Fundamental São João Batista

Com estas respostas pode-se constatar que a maioria da comunidade utiliza água de poços artesianos e por isso valorizam a sua preservação bem como fazem economia da mesma devido ao fato de não ser abundante principalmente a que é consumida para tomar.

O estudo constatou que a maioria acha que a água de boa qualidade faz bem a saúde e que a comunidade é bem cuidadosa e preocupada com a questão da água tanto que fazem economia e procuram passar esta cultura a seus filhos o que é muito importante para preservação do meio ambiente.

O homem cria a cultura na medida em que, integrando-se nas condições de seu contexto de vida, reflete sobre ela e dá respostas aos desafios que encontra. Cultura, aqui, é entendida como:

Os pais também foram unânimes quanto a importância da Educação Ambiental e a contribuição que esta traz como forma de preservar não só a água mas toda natureza.

As questões respondidas pelos alunos também foram de grande importância para o desenvolvimento do trabalho uma vez que se percebeu o interesse dos alunos na realização do trabalho principalmente quanto à preservação da água e a sua economia como forma de ajudar o meio ambiente.

Percebeu-se que a maioria das crianças se inteirou bem do assunto ao mesmo tempo em que conseguiram assimilar as formas de realizar sua economia de maneira simples, e que com isto já estão contribuindo para sua preservação. 
Foi realizada uma produção textual quando os alunos tiveram que dar continuidade a uma historinha que falava de uma gotinha que estava sempre em busca de aventuras "Gotinha de Cristal", depois cada aluno leu a sua para os colegas e foi feito uma votação onde foram escolhida as mais criativas, os alunos do 10 ano como não sabem escrever ouviram as historinhas e realizaram um desenho.

$\mathrm{Na}$ realização dos jogos todos os alunos participaram na montagem dos quebra cabeças sobre onde se encontra a água na natureza só $01^{\circ}$ que encontrou um pouco de dificuldade, sendo que os outros os ajudaram a montar.

No jogo da trilha os alunos jogavam um dado e iam respondendo as questões sobre a água que foram feitas em fichas e colocadas no chão na medida em que respondiam seguiam adiante até chegar a linha de chegada.

No passeio que foi realizado na casa dos alunos podemos ver de perto a realidade em que eles vivem, pois como já foi dito antes a maioria depende da água de poços artesianos.

A comunidade é bastante participativa na escola e sempre procura estar presente das atividades propostas incluindo este trabalho que foi realizado.

Em primeiro lugar, gostaria de destacar o fato de que as atividades propostas tiveram um numero muito expressivo de colaboração tanto por parte dos alunos como dos pais. Os resultados deste estudo em relação às questões respondidas pelos pais de 1 a 10 foram analisadas conforme a tabela1, referente à importância da água e de sua preservação para ao meio ambiente.

Aos alunos foram distribuídos 10 questionários os quais foram respondidos aos alunos do 20 ano, da terceira série 4 을 sére, sendo que os alunos do primeiro ano não responderam. Também foi realizado pelos alunos uma produção textual

As turmas são distribuídas em 10ano que são 5 alunos, 20 ano que são 8 alunos, $3^{a}$ série que consta de um aluno e a $4^{a}$ a serie que também consta de um aluno, a escola ainda trabalha com classes multiseriadas o que não impediu a realização do estudo, juntamos as turmas para responderem ao questionário em aula.

Os jogos e brincadeiras tiveram a participação de todos os alunos.

Nós, enquanto educadores precisamos continuar colaborando com a história do planeta mostrando a nossos alunos a realidade em que vivemos e buscar soluções que ajudem a minimizar os problemas em relação ao Meio Ambiente.

\section{CONSIDERAÇÕES FINAIS}

Este estudo mostra os resultados de um trabalho de educação ambiental realizado nas séries iniciais do ensino fundamental, no Colégio São João Batista em Formigueiro.

O trabalho realizado foi muito gratificante, pois, além da satisfação dos alunos, conseguiu-se finalizar todas as atividades propostas, chegando ao resultado desejado, que foi o de sensibilizá-los sobre o que se passa em nosso dia-a-dia e como fazer para melhorarmos o meio em que vivemos, prestando a atenção em nossas próprias ações, para com o meio ambiente.

É importante ressaltar que é preciso que a escola esteja sempre buscando alternativas para trabalhar o tema meio ambiente dando ênfase ao desenvolvimento de novas atitudes onde professor e aluno sejam participantes efetivos na realização da educação ambiental. 


\section{REFERÊNCIAS BIBLIOGRÁFICAS}

BATALHA, B. A água que você bebe. São Paulo: CTESB, 1985, p. 101. BRASIL. Ministério do Meio Ambiente. Secretaria de Recursos Hídricos. Águas subterrâneas: Conceito, reservas, usos e mitos. Brasília: 1997.

BRASIL. LEI no. 9.795 de 27 de abril de 1999. Política Nacional de Educação Ambiental. 1999.

CHOW, V. T. Open Channel Hydraulics. New York: Ed. McGraw-Hill, 1959, 680 p.

DECLARAÇÃO dos Direitos Humanos. United Nations Information Center. Disponível em: HTTP://www.unchr.chudrh/lag/por/htm, acesso em 20/10/2009.

DIAS, G. F. Educação Ambiental: princípios e práticas. São Paulo: Gaia, 2001.

KAISER, B. Dez mil anos de descobertas. São Paulo: Ed. Melhoramentos. 1952. 287 p.

KRAMER, P.J. \& BOYER, Water relations of plants and soils. New York. Ed. MacGraw-Hill, 1995. 482 p.

SANTOS, F. A.; IGLESIAS, W. Abastecimento de água. V. 1. São Paulo: Panorama Setorial, Gazeta Mercantil, junho de 2001, p.7.

SELBORNE, Lord. A Ética do Uso da Água Doce: Um levantamento. 1a edição. Brasília, DF: UNESCO, 2002. 80p.

TOZONI-REIS, M.F.C. Contribuições para uma pedagogia crítica na educação ambiental: reflexões teóricas. In: LOUREIRO, C. F. B. A questão ambiental no pensamento crítico: natureza, trabalho e educação. Rio de Janeiro: Quartet, 2007, p.9.

TUCCl, Carlos E.M., et al. Gestão da Àgua no Brasil. 1a edição. Brasília, DF: UNESCO, 2001. 192p.

VALLE, C.E. Qualidade Ambiental - 0 Desafio de Ser Competitivo Protegendo o Meio Ambiente. São Paulo: Ed. Pioneira, 1995.

VASCONCELOS SOBRINHO J. A Ecologia na Gestão dos Recursos Hídricos para as Regiões Semi-áridas do Nordeste Brasileiro. Revista Pernambucana de Desenvolvimento. V7,no1, p.65-77, jan/jul, Recife.1980. 